\title{
PD-L1 expression on immune cells is a favorable prognostic factor for vulvar squamous cell carcinoma patients
}

\author{
Jacek J. Sznurkowski ${ }^{1}$, Anton Żawrocki², Katarzyna Sznurkowska ${ }^{3}$, Rafał Pęksa² \\ and Wojciech Biernat ${ }^{2}$ \\ ${ }^{1}$ Department of Oncological Surgery, The Medical University, Gdańsk, Poland \\ ${ }^{2}$ Department of Pathology, The Medical University, Gdańsk, Poland \\ ${ }^{3}$ Department of Pediatrics, Pediatric Gastroenterology, Hepathology and Nutrition, The Medical University, Gdańsk, Poland \\ Correspondence to: Jacek J. Sznurkowski, email: jacek.sznurkowski@gumed.edu.pl \\ Keywords: vulvar SCC, PD-L1, HPV, p16, prognosis \\ Received: July 13,2017 Accepted: August 29, $2017 \quad$ Published: September 15, 2017 \\ Copyright: Sznurkowski et al. This is an open-access article distributed under the terms of the Creative Commons Attribution License \\ 3.0 (CC BY 3.0), which permits unrestricted use, distribution, and reproduction in any medium, provided the original author and \\ source are credited.
}

\section{ABSTRACT}

Background: Anti-immune programmed death-ligand 1 (PD-L1) pathway is used by the tumor to overcome immune system and serves as immunotherapy target in various malignancies.

Aim: To investigate the expression of PD-L1 in vulvar squamous cell carcinoma (vSCC) and to assess it's clinicopathological and prognostic significance.

Methods: Immunohistochemical PD-L1 expression was evaluated in 84 vSCCs with previously defined status of p16 and DNA-HPV, infiltration of immune cells: CD8+, CD4+, FOXP3+, CD56+, CD68+, and GZB+ cells. PD-L1 positivity was defined as $\geq 5 \%$ of PD-L1-positive cells. Survival analyses included the Kaplan-Meier method, log-rank test and Cox proportional hazards model.

Results: PD-L1 expression was detected on cancer and peritumoral immune cells. PD-L1-positivity of cancer nests $(27 / 84,32.1 \%)$ was correlated with higher infiltration of CD4+ $(p=0.037), C D 8+(p=0.02)$, FOXP3 + $(p=0.007), C D 68+(p=0.021)$ cells, while PD-L1 positivity of peritumoral immune cells $(51 / 84,60.7 \%)$ was correlated with higher infiltration of intraepithelial FOXP3+ cells only $(p=0.037)$.

PD-L1-positivity of cancer cells but not immune cells, was more frequently observed in $\mathrm{p} 16-$ negative tumors $(\mathrm{p}=\mathbf{0 . 0 0 4})$. High-risk HPV-status did not correlate with the PD-L1 status of cancer and immune cells $(p=1.000)$ and $(p=1.000)$ respectively). Median follow up was 89.20 months (range 1.7-189.5). PD-L1 positivity of peritumoral immune cells was found to be an independent favorable prognostic factor for OS. Conclusion: This study highlights the importance of comprehensive PDL1 assessment in both cancer and immune cells. PD-L1 expression on peritumoral immune cells seems to be an additional prognostic factor in vSCC patients and may influence the results by anti-PD-L1 treatment.

\section{INTRODUCTION}

The immune microenvironment of vulvar squamous cell carcinoma (vSCC) has been studied intensively by our group [1-3] and the others [4]. Lack of prognostic significance of adaptive immune effectors and regulatory
T cells described in these studies has indirectly suggested limited role for immunotherapy for vulvar cancer patients.

Recently, we have found that cancer immune surveillance as represented by tumor infiltrating lymphocytes (TILs) and tumor associated macrophages (TAMs) depends on $\mathrm{p} 16^{\mathrm{INK} 4 \mathrm{a}}$ expression regardless to high- 
risk HPV-DNA status [5] as various immune effectors contribute to improved clinical outcomes in patients with p16-positive and p16 $6^{\mathrm{INK} 4 \mathrm{a}}$-negative tumors.

This suggests that not HPV infection itself, but p $16^{\mathrm{INK} 4 \mathrm{a}}$ overexpression, contributes to shaping of the tumor microenvironment and p $16^{\mathrm{INK} 4 \mathrm{a}}$-status could stratify patients for separate immunotherapeutic approaches in vSCC.

Recently, there has been a breakthrough in cancer immunotherapy against various cancer types by employing immune checkpoint blockade, particularly using antibodies directed against programmed deathligand 1 (PD-L1) pathway members [6].

PD-L1 (also called B7-H1 or CD274), which is expressed on many cancer and immune cells, plays an important part in blocking the 'cancer immunity cycle' [7] by binding programmed death-1 (PD-1) and B7.1 (CD80), both of which are negative regulators of T-lymphocyte activation [6].

This study aimed to evaluate PD-L1 expression in vSCC tumors and to look for the correlation of this biomarker with clinical and pathological features of vSCC patients including TILs, TAMs as well as $\mathrm{p} 16^{\mathrm{INK} 4 \mathrm{a}}$ and high risk (hr) DNA-HPV status in the primary tumor.

\section{RESULTS}

\section{Patterns of PD-L1 expression}

PD-L1 expression was detected on cancer cells (CCstars) and tumor-infiltrating immune cells (IC-arrows) (Figure 1).

In 27 of 84 tumors (32.1\%) PD-L1 positive CC were found while PD-L1 positivity in peritumoral immune cells was disclosed in 51 of $84(60.7 \%)$ cases.

Lack of PD-L1 expression (CC-PD-L1 and ICPD-L1 negative tumors) was observed in 26 of 84 (31\%) vSCC. Dual expression of PD-L1 (CC-PD-L1 and ICPD-L1 positive tumors) was notified in 20 of 84 (23.8\%) cases. PD-L1 was exclusively expressed on cancer (CCPD-L1 positive and IC-PD-L1 negative) and immune cells (CC-PD-L1 negative and IC-PD-L1 positive) in $7 / 84(8.3 \%)$ and $31 / 84(36.9 \%)$ case respectively. Detected variants of PD-L1 expression are depicted on Figure 2.

\section{Association between PD-L1 expression and intraepithelial immune infiltrates}

CC-PD-L1-positivity was correlated with higher intraepithelial infiltration of CD4+ $(p=0.037), \mathrm{CD} 8+$ $(p=0.02), F O X P 3+(p=0.007), C D 68+(p=0.021)$ immune cells (Table 1).

IC-PD-L1-positivity of vSCC was correlated only with higher intraepithelial infiltration of FOXP3+ cells $(\mathrm{p}=0.037)$ (Table 1).

\section{Association of PD-L1 expression with $\mathrm{p} 16$ and high risk (hr) HPV statuses}

CC-PD-L1-positivity was frequently observed in p16-negative vSCCs $(\mathrm{p}=0.004)$.

CC-PD-L1-positivity was similar in (hr)HPV-DNA positive and negative vSCCs $(\mathrm{p}=1.000)$.

Lack of difference in IC-PD-L1-positivity was observed in cases with mutually excluding p16 and (hr) HPV-DNA status ( $\mathrm{p}=1.00$ and $\mathrm{p}=1.00$, respectively).

\section{Association of PD-L1 expression with common clinicopathological features}

CC-PD-L1 and IC-PD-L1-positivity did not depend on $\mathrm{pT}$ (Fisher's exact test) $(\mathrm{p}=0.748$ and $\mathrm{p}=0.158)$, presence of lymph node metastases $(p=0.640$ and $\mathrm{p}=0.656)$, tumor differentiation grade $\mathrm{G} 1 / \mathrm{G} 2,3 \quad(\mathrm{p}=1$ and $p=0.815)$, (Mann-Whitney $U$ test) age $(p=0.523$ and $p=0.072)$ and depth of invasion $(p=0.361$ and 0.502$)$ respectively (Table 2 ).

\section{Survival analyses}

\section{Entire cohort}

CC-PD-L1-positivity did not influence prognosis of vSCC patients ( $p=0.164)$ (Figure 3A).

Patients with primary tumors positive for IC-PD-L1 expression had improved OS compared to IC-PD-L1 negative ones $(\mathrm{p}=0.017)$ (Figure 3B).

\section{Variants of PD-L1 positivity}

In the next step, the cohort of $84 \mathrm{vSCC}$ patients was divided into four groups based on variants of CC-PD-L1 and IC-PD-L1-positivity: CC-PD-L1(+)/IC-PD-L1(-) n=7; CC-PD-L1(+)/IC-PD-L1 (+) n= 20; CC-PD-L1(-)/ IC-PD-L1(+) n=31 and CC-PD-L1(-)/IC-PD-L1(-) n=26.

Survival analyses comparing all variants of $\mathrm{PD}$ L1 expression indicated the group of patients with $\mathrm{CC}$ PD-L1(-)/IC-PD-L1(+) tumors presented trend towards significantly better prognosis $(p=0.061)$ (Figure 3C). When this group was further compared to the rest of cohort taken together it revealed significantly best outcome $(\mathrm{p}=0.002)$ (Figure 3D).

\section{P16 $^{\text {INK4a }}$ status}

Additionally, impact of PD-L1-positivity on survival was assessed in groups of patients with different $\mathrm{p} 16^{\mathrm{INK} 4 \mathrm{a}}$ status.

CC-PD-L1-positivity did not influence the overall survival in cases having tumors $\mathrm{p} 16^{\mathrm{INK} 4 \mathrm{a}}$-negative and $\mathrm{p} 16^{\mathrm{INK} 4 \mathrm{a}}$-positive $(\mathrm{p}=0.3763$ and $\mathrm{p}=0.1639$ respectively).

IC-PD-L1-positivity improved overall survival in cases with $\mathrm{p} 16^{\mathrm{INK} 4 \mathrm{a}}$-positive tumors $(\mathrm{p}=0.0271)$ while it was not prognostic for patients with $\mathrm{p} 16^{\mathrm{INK} 4 \mathrm{a}}-$ negative tumors $(\mathrm{p}=0.0821)$ (Figure 4$)$. 


\section{Univarialble and multivariable analyses}

Univariate and multivariate analyses revealed that IC-PD-L1-positivity was an independent prognostic factor for OS in vSCC patients (Tables 3 and 4).

\section{DISCUSSION}

In the present study, we comprehensively evaluated PD-L1 expression on the whole sections of tumor tissue showing that this biomarker is present both on cancer and immune cells. In our opinion assessment of macrodissected cancer tissue is superior than evaluation of tumor microarrays (TMAs). Compared with the whole tumor sections, tumor microarrays (TMAs) may be less representative, especially while assessing the biomarkers expressed in the tumor infiltrating immune cells [8].

PD-L1 positivity was defined as $\geq 5 \%$ of cells regardless the intensity of membranous staining. This is consistent with several publications analyzing this biomarker within other malignancies [9-12]. An appropriate cutoff value in validating the positive expression of PD-L1 remains contentious. Subgroup analysis with different cutoff values has shown that there was a contradictory trend when using the cutoff value of ' $5 \%$ ' or ' $1 \%$ ' in evaluating the correlations of PD-L1 positive expression with survival of cancer patients [8]. Therefore, a combined classification of cutoff values for PD-L1 assessment in CCs and ICs seems feasible and reasonable.
PD-L1-positivity of immune cells was more frequently observed within vSCC than PD-L1-positivity of cancer cells $(60.7 \%$ vs. $32.1 \%)$. We found only two publications dealing with PD-L1 in vulvar cancer $[13,14]$. None of these papers provided data neither on patterns of PD-L1 staining within primary tumor nor on frequency of PD-L1 expression in vSCC.

Recently we have reported that $\mathrm{p} 16^{\mathrm{INK} 4 \mathrm{a}_{-}}$ overexpression modulates immune cells infiltration regardless to (hr)HPV-DNA status [5]. Patients with p16 $6^{\mathrm{INK} 4 \mathrm{a}}$-negative tumors although more infiltrated with TILs (CD8+, CD4+, GZB+ cells) had worse outcome than cases with p16 $6^{\mathrm{INK} 4 \mathrm{a}}$-positive vSCCs $[5,15]$. Here CC-PD-L1 expression was frequently observed on more infiltrated $\mathrm{p} 16^{\mathrm{INK} 4 \mathrm{a}}$-negative vSCCs suggesting that antiimmune programmed death-ligand 1 (PD-L1) pathway is at least partially responsible for worse outcome in these patients. However, CC-PD-L1 did not reveal prognostic significance either in entire cohort nor in patients with p1 $6^{\text {INK4a }}$-negative tumors.

The mechanism by which CC-PD-L1 surface expression is induced is quite ambiguous and includes either immune cell and cancer cells. Besides adaptive PD-L1 up-regulation in an inflammatory cytokine milieu caused by TAMs and/or Interferon- $\gamma$ [16-18], cancers can have innate potential to drive PD-L1 expression by oncogene. Several genetic alterations were associated with constitutive PD-L1 up-regulation, like PTEN loss or NPM/ ALK $[19,20]$. Amplification at 9p24.1, where PD-L1 resides, has been associated with PD-L1 up-regulation in

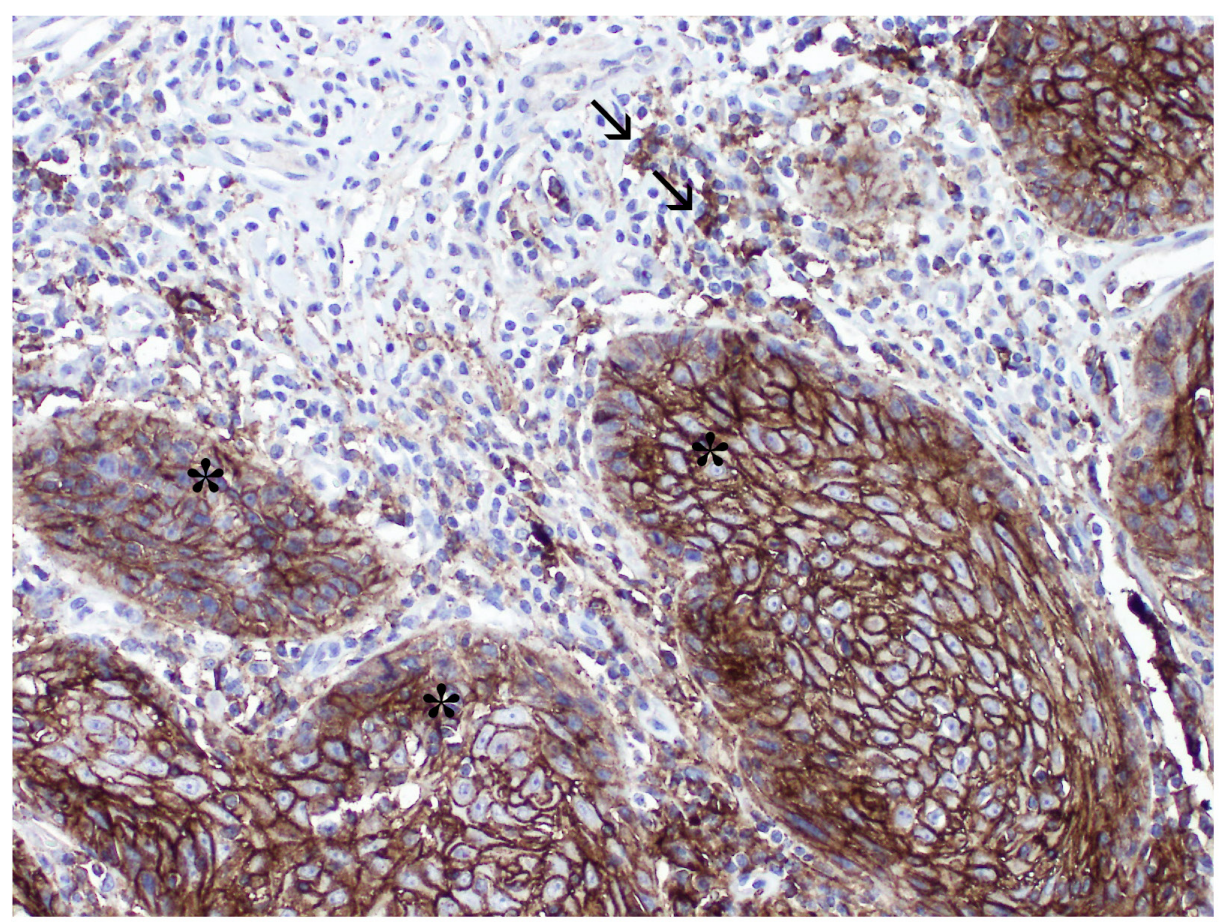

Figure 1: Microphotograph of immunohistochemical staining for PD-L1 within primary vSCC: (stars) expression on cancer cells, (arrows) expression on immune cells. 
Table 1: Correlation between CC-PD-L1 expression and subtypes of intraepithelial (IE) tumor infiltrating immune cells

\begin{tabular}{lcccccc}
\hline & $\begin{array}{c}\text { TC-PD- } \\
\text { L1(pos.) }\end{array}$ & $\begin{array}{c}\text { TC-PD- } \\
\text { L1(neg.) }\end{array}$ & pUMW & IC-PD-L1(pos.) & IC-PD-L1(neg.) & pUMW \\
\hline $\begin{array}{l}\text { CD 4+ median } \\
\text { (range) }\end{array}$ & $4(0-21.66)$ & $0(0-18.33)$ & $\mathbf{0 . 0 3 7}$ & $3(0-21.66)$ & $0(0-19.66)$ & 0.061 \\
$\begin{array}{l}\text { CD 8+ median } \\
\text { (range) }\end{array}$ & $30.66(0-214.33)$ & $12.33(0-121)$ & $\mathbf{0 . 0 0 2}$ & $16(0-214.33)$ & $18.66(0-101)$ & 0.591 \\
$\begin{array}{l}\text { FOXP3+ median } \\
\text { (range) }\end{array}$ & $17.5(4.16-66)$ & $11.33(0-58.4)$ & $\mathbf{0 . 0 0 7}$ & $17.8(0-66)$ & $9.28(0-35.33)$ & $\mathbf{0 . 0 0 2}$ \\
$\begin{array}{l}\text { CD56+ median } \\
\text { (range) }\end{array}$ & $2(0-12.66)$ & $2(0-37)$ & 0.520 & $2(0-37)$ & $1.66(0-29)$ & 0.163 \\
$\begin{array}{l}\text { GZB+ median } \\
\text { (range) }\end{array}$ & $3.33(0-13.33)$ & $2.83(0-14.33)$ & 0.303 & $3.33(0-14.33)$ & $3(0-10)$ & 0.183 \\
$\begin{array}{l}\text { CD68+ median } \\
\text { (range) }\end{array}$ & $11.33(0-20.33)$ & $7.33(0-19.66)$ & $\mathbf{0 . 0 2 1}$ & $8.5(0-20.33)$ & $7.66(0-19.66)$ & 0.607 \\
\hline
\end{tabular}

oral squamous cell carcinoma [21] and non-small cell lung cancer [22]. Activation of PI3K pathway by PTEN loss in both breast cancers [23] and glioblastomas [19] has been shown to induce PD-L1 expression. These events have long been known to result in the expression of neoantigens, differentiation antigens, or cancer testis antigens, which can lead to presentation of peptides bound to major histocompatibility class I molecules on the surface of cancer cells, distinguishing them from their normal counterparts [7]. This could partially explain, observed in this study, correlation between CC-PD-L1-postivity and higher intraepithelial immune infiltration as represented by $\mathrm{CD} 4+, \mathrm{CD} 8+, \mathrm{FOXP} 3+\mathrm{T}$ cells. Additionally, CCPD-L1-positivity was more frequently observed among

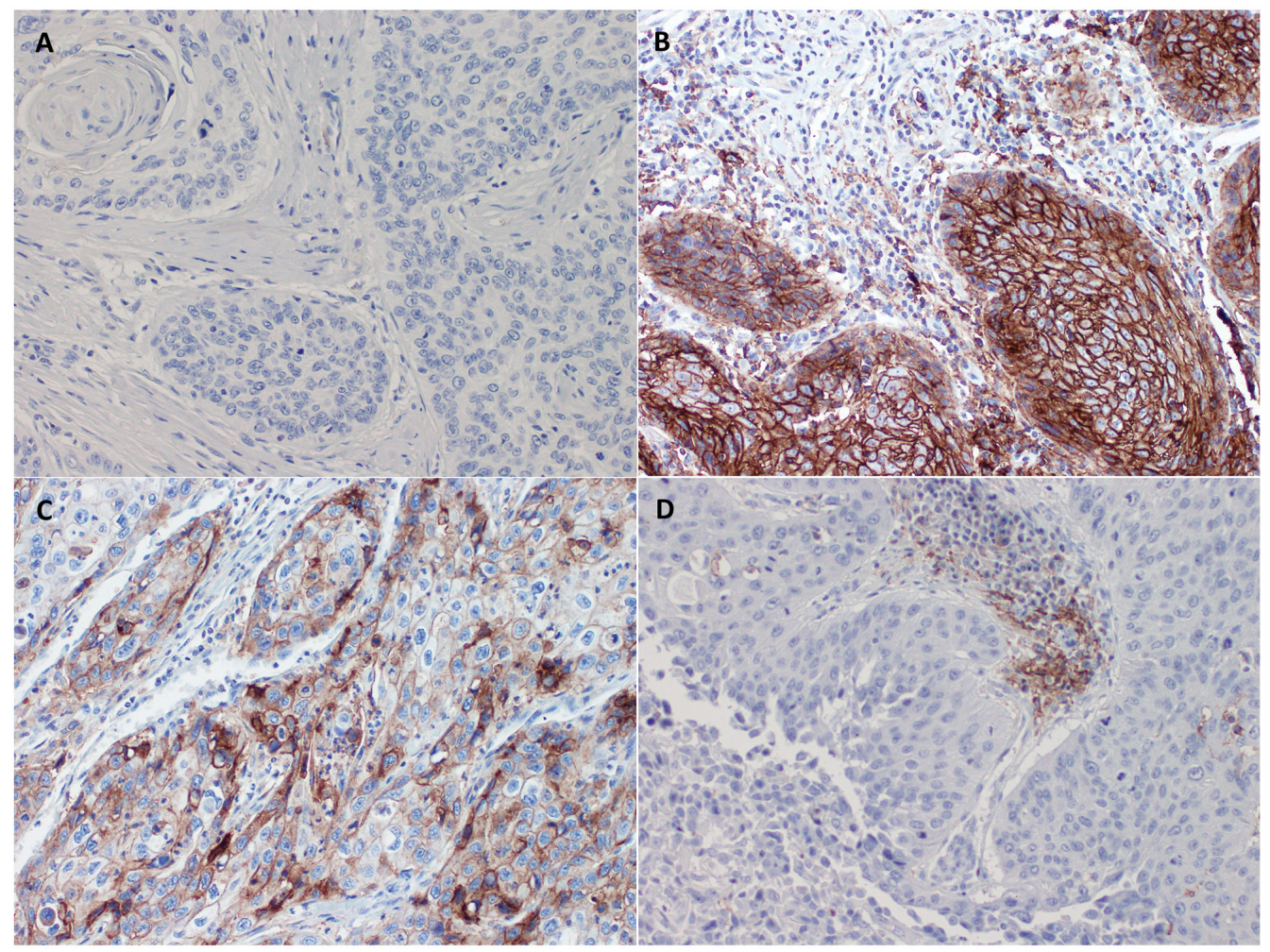

Figure 2: Microphotograph of immunohistochemical staining for CC-PD-L1/IC-PD-L1 variants within primary vSCC: (A) CC-PD-L1(+)/ IC-PD-L1(+); (B) CC-PD-L1(-)/IC-PD-L1(-); (C) CC-PD-L1(+)/IC-PD-L1(-); (D) CC-PD-L1/IC-PD-L1(+). 
Table 2: Association between PD-L1-positivity and clinicopathological features of vSCC patients

\begin{tabular}{lcccccc}
\hline & CC-PD-L1(pos.) & CC-PD-L1(neg.) & $\mathbf{p}$ & IC -PD-L1(pos.) & IC -PD-L1(neg.) & p \\
\hline pT 1/2/3 & $24 / 3 / 0$ & $51 / 5 / 1$ & $\mathrm{p}=0.748$ & $48 / 3 / 0$ & $27 / 5 / 1$ & $\mathrm{p}=0.158$ \\
Meta +/- & $14 / 13$ & $25 / 32$ & $\mathrm{p}=0.640$ & $25 / 26$ & $14 / 19$ & $\mathrm{p}=0.656$ \\
Grade 1/2+3 & $9 / 18$ & $18 / 39$ & $\mathrm{p}=1.000$ & $17 / 34$ & $\mathrm{p}=0.815$ \\
Age & $68(36-82)$ & $68(40-85)$ & $\mathrm{p}=0.523$ & $66(36-85)$ & $71(44-85)$ & $\mathrm{p}=0.072$ \\
Depth of invasion & $7.0(2.0-18.0)$ & $7.6(2.0-16.0)$ & $\mathrm{p}=0.361$ & $7.0(2.0-18.0)$ & $7.5(2.0-13.0)$ & $\mathrm{p}=0.502$ \\
\hline
\end{tabular}

p16 $6^{\text {Ink4a }}$-negative tumors which were found to be more infiltrated by TILs and TAMs [5]. Lack of prognostic effect of interaction between PD-L1 on cancer cells and PD-1 on TILs can reflect state of equilibrium between host immune response and cancer tissue, thus not influencing patient's overall survival.

Interestingly, PD-L1-positivity of immune cells was found to be independent prognostic factor for overall survival of vSCC patients. Similar findings were published for head and neck cancer patients suggesting that comprehensive assessment of PD-L1 expression could bring an information for more precise usage check point inhibitors [9]. Recent meta-analysis of prognostic value of PD-L1 expression on tumor infiltrating immune cells, including 3674 patients with different types of cancers, confirmed that IC-PD-L1 is related to a better survival of cancer patients [8].

Several previous reports have shown that PD-L1 expression is a negative prognostic factor in several cancer types, including renal, colorectal, and lung cancers [24-
A
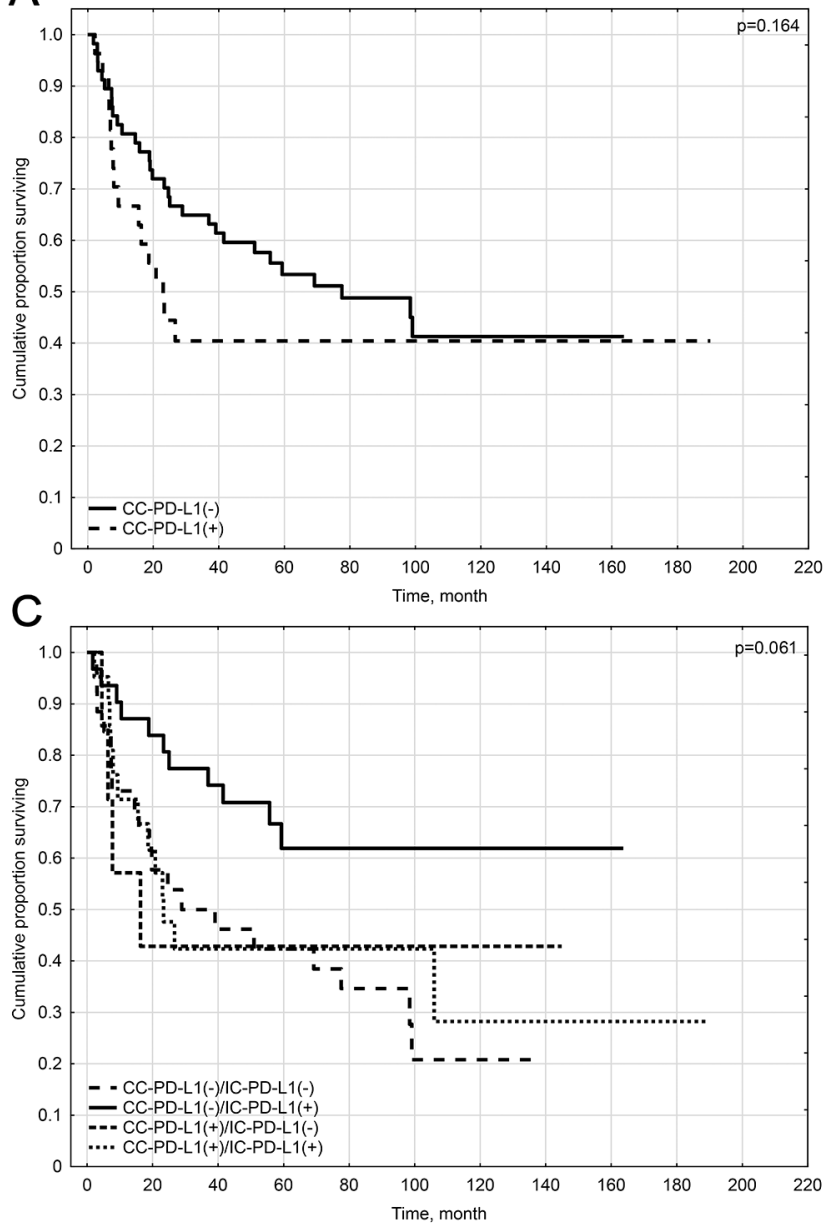

B
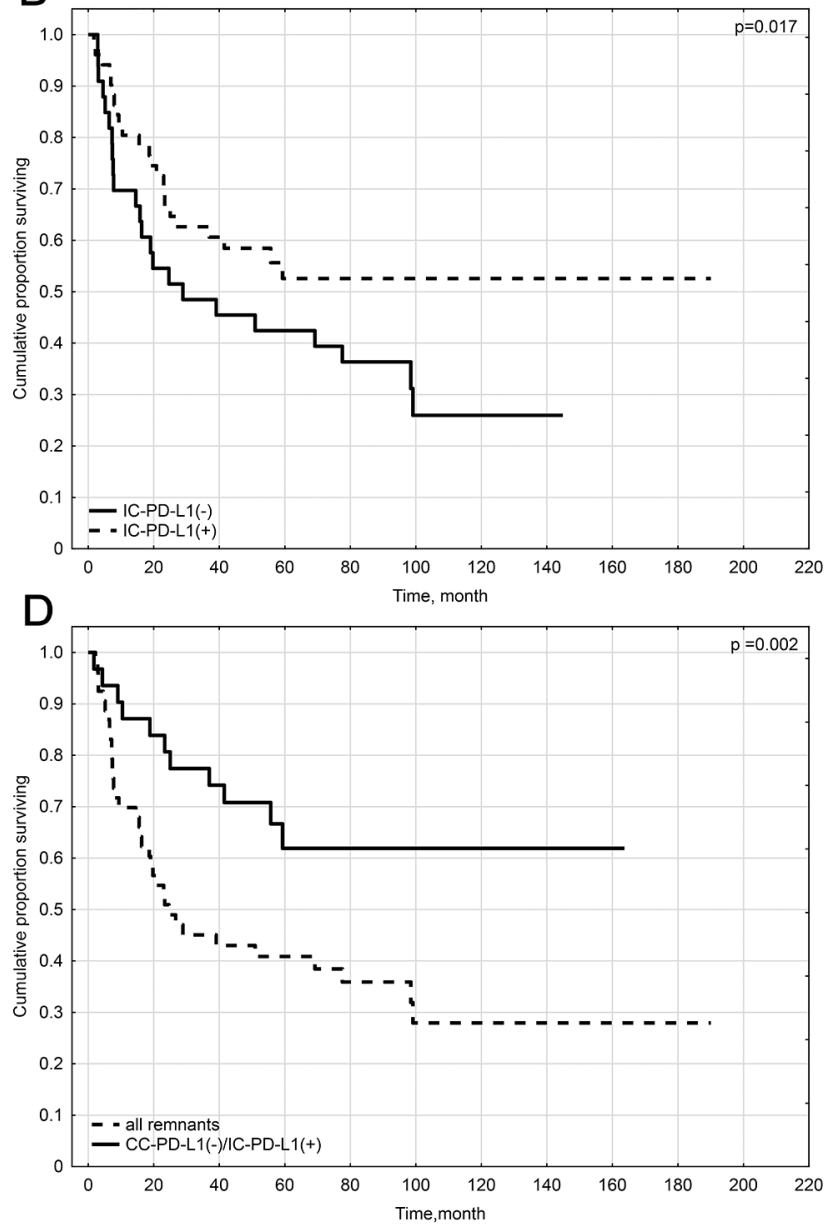

Figure 3: Kaplan-Meier survival curves for overall survival of patients by: (A) PD-L1-positivity of cancer nests in general population. (B) PD-L1-positivity of peritumoral immune cells in general population. (C) All Variants of CC-PD-L1 and IC-PD-L1 positivity in general population. (D) IC-PD-L1 positivity versus remaining variant of CC-PD-L1 and IC-PD-L1 positivity. 
26], but others have reported that PD-L1 is a favorable prognostic factor in metastatic melanomas, NSCLC, and Merkel cell carcinomas [27-29]. In the majority of these studies, the expression of PD-L1 in tumor sections has been evaluated without exact discrimination between IC and TC.

Notably, we have found that IC-PD-L1-positivity improves survival in entire cohort, but when the patients were subdivided into two groups based on $\mathrm{p} 16^{\mathrm{INK} 4 \mathrm{a}}$-status of the primary tumor, this protective effect was observed only for p16 $6^{\mathrm{INK} 4 \mathrm{a}}$-positive cases. (hr)HPV-DNA status did not influenced PD-L1-positivity either on cancer and immune cells which supports our previous results suggesting lack of clinicopathological significance of HPV-DNA positivity within VSCC $[5,15]$.

When we separately analyzed PD-L1-positivity on $\mathrm{CC}$ and IC, which was categorized into four variants of vSCC cases, we found that patients with CC-PD-L1(-)/ IC-PD-L1(+) tumors had significantly best outcome.

Few hypotheses could explain this paradoxical favorable prognosis of PD-L1 expression on ICs. IC-PD-L1 expression could be driven by adaptive mechanisms such as exogenous inflammation mediated immune attack and then reflected pre-existing immunity [9, 30]. IC-PD-L1-positivity could have stronger relations
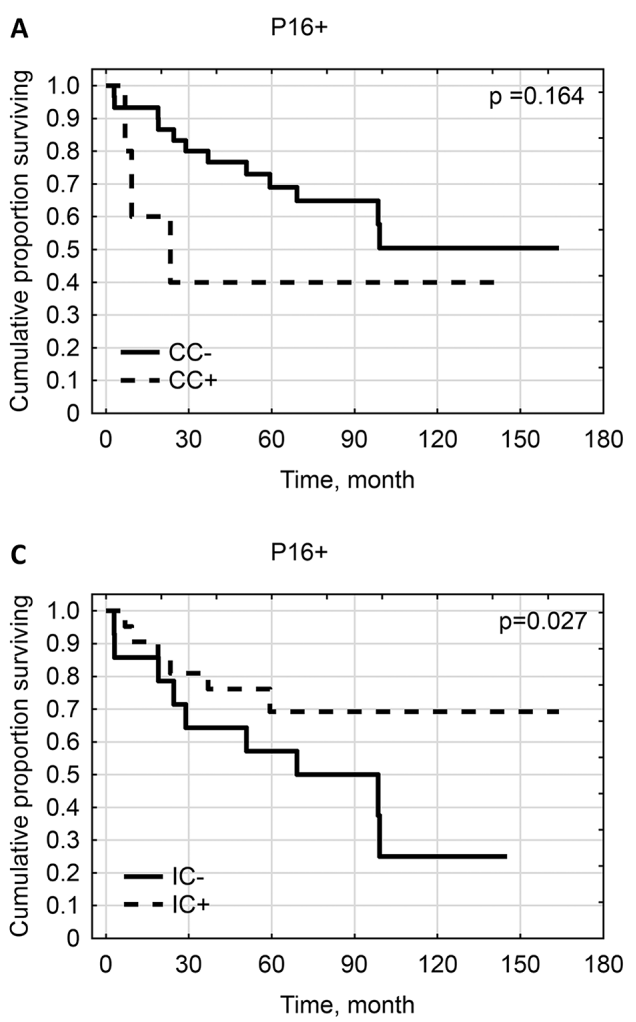

with cancer immune response, and probably depends on tumor microenvironments. Such favorable profile of immune microenvironments was described for PD-L1 expression in pulmonary squamous cell carcinoma [12].

Here, IC-PD-L1-positivity was correlated with unfavorable intraepithelial FOXP3+ lymphocytes while CC-PD-L1-positivity was correlated with favorable CD4+, CD8+ as well as unfavorable FOXP3+and CD68+ immune cells. Thus, indication of more favorable preexisting immunity remains unclear.

However, with the exception of PD-L1 expression all other data were retrieved from our previous studies, originality of current report is supported by completely new study project and design. Immunohistochemical PD-L1 expression has never been analyzed before within vulvar cancer tissue. By analyzing all available data for this cohort, we were able to present in single publication, not only patterns of expression and prognostic significance of this biomarker but also associations with TILs, TAMs, p16 $6^{\mathrm{INK} 4 \mathrm{a}}$ and (hr)HPV-DNA status. Such correlations have never been described before.

This study provides a new insight into immune surveillance on vSCC as for the first time demonstrates that although PD-L1 could mediate the occurrence of cancer immune escape, it also indicates an effective immune response.
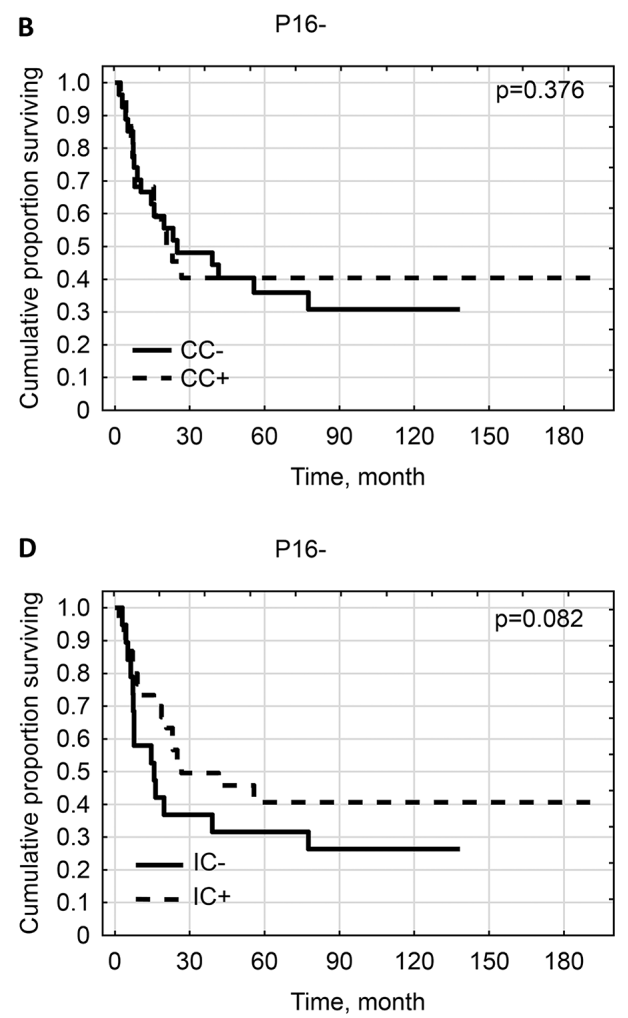

Figure 4: Kaplan-Meier survival curves for overall survival of patients by: (A) CC-PD-L1-positivity in population of patients with p16-positive tumors. (B) CC-PD-L1-positivity in population of patients with p16-negative tumors. (C) IC-PD-L1positivity in population of patients with p16-positive tumors. (D) IC-PD-L1-positivity in population of patients with p16negative tumors. 
Table 3: Univariate analyses of survival in vulvar cancer patients

\begin{tabular}{|c|c|c|c|c|}
\hline \multirow[t]{2}{*}{ Variables } & \multirow[t]{2}{*}{ Categories } & \multicolumn{2}{|c|}{ Overall survival } & \multirow[t]{2}{*}{$\mathbf{p}$} \\
\hline & & HR & $95 \%$ CI & \\
\hline \multirow{2}{*}{ Nodal status } & metastases (-) & 1 & \multirow{2}{*}{$1.59-5.22$} & \multirow{2}{*}{0.0005} \\
\hline & metastases $(+)$ & 2.88 & & \\
\hline \multirow{2}{*}{ Adjuvant RTX } & Yes & 1 & \multirow{2}{*}{$2.22-7.30$} & \multirow{2}{*}{0.000005} \\
\hline & No & 4.02 & & \\
\hline \multirow{2}{*}{ Histologic grade } & Low (G1) & 1 & \multirow{2}{*}{$1.65-7.15$} & \multirow{2}{*}{0.001} \\
\hline & High $(\mathrm{G} 2+\mathrm{G} 3)$ & 3.43 & & \\
\hline \multirow{2}{*}{ p16 status } & Positive & 1 & \multirow{2}{*}{$1.11-3.81$} & \multirow{2}{*}{0.0216} \\
\hline & Negative & 2.06 & & \\
\hline FIGO stage & I,II,III,IV & 1.62 & $1.23-2.12$ & 0.000592 \\
\hline Depth of invasion & Continuous & 1.05 & $0.96-1.15$ & 0.283261 \\
\hline \multirow{2}{*}{ Age } & $<60$ & 1 & \multirow{2}{*}{$1.12-5.59$} & \multirow{2}{*}{0.025436} \\
\hline & $>60$ & 2.5 & & \\
\hline \multirow{2}{*}{ IC-PD-L1 } & negative & 1 & \multirow{2}{*}{$0.32-1.03$} & \multirow{2}{*}{0.0065} \\
\hline & positive & 0.57 & & \\
\hline
\end{tabular}

Table 4: Multivariate analyses of survival in vulvar cancer patients

\begin{tabular}{lcccc}
\hline Variables & Categories & \multicolumn{2}{c}{ Overall survival } & p \\
\cline { 3 - 4 } & & HR & 95\% CI & \\
Nodal status & $\begin{array}{c}\text { Negative for } \\
\text { metastases }\end{array}$ & 1 & $1.50-5.02$ & 0.019 \\
& Positive for metastases & 2.74 & & \multirow{2}{*}{0.007} \\
Histologic Grade & Low (G1) & 1 & $1.33-5.90$ & \\
High (G2+G3) & Positive & 2.80 & & 0.001 \\
p16 status & Negative & 1 & $1.13-3.95$ & \\
IC-PD-L1 & negative & 2.11 & & 0.010 \\
\hline
\end{tabular}

The weaknesses of the current study are the retrospective design and the small size of cohort involved. Its strength lies in the consistency of the treatment of patients under uniform standards and their long observation, revealing recurrences and hence enabling the assessment of the prognostic significance of all the analyzed biomarkers.

\section{MATERIALS AND METHODS}

This retrospective study was approved by the Polish Ministry of Science and Higher Education review board, who determined that further informed consent was not required as informed consent for tissue sampling was obtained from all patients prior to surgical treatment and written consent was given by the patients for their information to be stored in the hospital database and used for research.

\section{Population}

Our cohort of 85 patients previously studied with known $\mathrm{p} 16^{\mathrm{INK} 4 \mathrm{a}}$ and (hr)HPV status [15], as well as TILs and TAMs [5] was included into further analyses. One case 
was excluded due to lack of tissue for PD-L1 staining. Briefly, the median age of the 84 patients was 68 years (range 36-85), the median duration of follow-up was 88.75 months (range 1.7-189.5), The 5-year disease free survival (DFS) rate was $61.75 \%$.

\section{Tissue samples}

We analyzed all 84 primary tumors for PD-L1 expression. Data on TILs were retrieved from our previous studies $[1-3,5]$. Data on $\mathrm{p} 16^{\mathrm{INK} 4 \mathrm{a}}$ and (hr)HPV status were retrieved from our recent study [15].

\section{Antibodies}

Mouse anti-human monoclonal antibody against PDL1 (clone 22C3, cat. No. M3653) was obtained from Dako Inc. Mouse anti-human monoclonal antibodies against CD4 (NCL-L-368), CD8 (NCL-L-295), CD56 (NCLCD56-1B), were obtained from Novocastra, Inc. Mouse anti-human monoclonal antibody against FOXP3 (cat. No ab20034) and CD68 (cat. No ab955) were obtained from Abcam, Inc. Mouse anti-human polyclonal antibody against Granzyme B (cat. No 760-4283) was obtained from Ventana Medical Systems, Inc. Mouse anti-human monoclonal antibody against p16 (cat. No sc-56330) was obtained from Santa Cruz Biotechnology Inc., USA [5].

\section{Immunohistochemistry}

Immunohistochemical staining for PD-L1 was performed as follows. Four-micron-thick serial sections were cut, placed onto slides, and deparaffinized. For epitope retrieval, slides were immersed in Target Retrieval Solution (pH 6.1; Dako Cytomation, Denmark) and heated in a pressure cooker. Then, they were incubated for $90 \mathrm{~min}$ with primary antibody (1:50 dilution, clone $22 \mathrm{C} 3$, cat. nr. M3653). The reaction was visualized using the EnVision FLEX (DAKO). Appropriate positive (tonsil) and negative (primary antibody replaced with normal mouse IgG at an appropriate dilution) controls were included in each staining. Immunohistochemistry results were evaluated by two independent pathologists blind to the clinical data.

PD-L1 cell expression was referred as positive if membranous staining was identified and showed a continuous honeycomb pattern. Cytoplasmic staining of PD-L1 was disregarded. Expression of PD-L1was categorized into two groups according to the percentage of PD-L1-positive cells. PD-L1 positivity was defined as $\geq 5 \%$ of cells regardless to intensity of membranous staining [9-12].

Immunohistochemical staining for other antibodies:

p16, CD8, CD4, FOXP3, CD68, CD56, GZB with evaluation and classification of TILs and p16 $6^{\mathrm{INK} 4 \mathrm{a}}$ status was previously described for this cohort by our group [5].

\section{Detection of high risk HPV-DNA}

Tissue dissection and DNA preparation as well as mucosal HPV DNA amplification and genotyping were detailed for this cohort in our other recent study [15].

\section{Statistical analysis}

The statistical analysis was performed using the Fisher's exact probability test. The difference between numerical variables was verified by Mann-Whitney U test.

Overall survival curves were estimated by the Kaplan-Meier method and compared by the two-sided Fox test. Univariate and multivariate analysis was performed using Cox regression model. $p$ values $<0.05$ were regarded as significant in all analyses.

All analyses were performed using the statistical software

Statistical 13 (Stat Soft Inc.).

\section{CONCLUSION}

PD-L1 expression on IC, not on CC, is independent predictor of favorable OS in surgically treated vSCC patients. Assessment of the expression of immune-related molecules in whole tissue section slides could produce evidence relevant to the appropriateness of treatment via immune checkpoint blockade.

Moreover, our findings highlight the importance of comprehensive assessment of both TC and IC in vSCC and suggest that usage of antibodies directed against PDL1-pathway seems to be favorable for subjects having tumors negative for PD-L1 peritumoral immune cells. Thus, incorporating peritumoral immune cells into the classification of PD-L1 expression seems to be necessary to select the beneficial vSCC patients for anti-PD-L1 treatment.

\section{Author contributions}

Study concepts and design: JJSz, Data acquisition: AZ, RP, JJSz. Quality control of data and algorithms: AZ, RP. Data analysis and interpretation: JJSz, AZ, KSz, WB. Statistical analysis: AZ, JJSz. Manuscript preparation: JJSz. Manuscript editing: JJSz, WB. Manuscript review: WB, JJSz, AZ, RP, KSz. All authors read and approved the final manuscript.

\section{CONFLICTS OF INTEREST}

The authors declare that there are no conflicts of interest. 


\section{FUNDING}

This work was supported by the Polish Ministry of Science and Higher Education grant no. N 40306631/3077 for JJSz.

\section{REFERENCES}

1. Sznurkowski JJ, Zawrocki A, Emerich J, Biernat W. Prognostic significance of CD4+ and CD8 $+\mathrm{T}$ cells infiltration within cancer cell nests in vulvar squamous cell carcinoma. Int J Gynecol Cancer. 2011; 21:717-21.

2. Sznurkowski JJ, Zawrocki A, Emerich J, Sznurkowska K, Biernat W. Expression of indoleamine 2,3-dioxygenase predicts shorter survival in patients with vulvar squamous cell carcinoma (vSCC) not influencing on the recruitment of FOXP3-expressing regulatory $\mathrm{T}$ cells in cancer nests. Gynecol Oncol. 2011; 122:307-12.

3. Sznurkowski JJ, Zawrocki A, Biernat W. Subtypes of cytotoxic lymphocytes and natural killer cells infiltrating cancer nests correlate with prognosis in patients with vulvar squamous cell carcinoma. Cancer Immunol Immunother. 2014; 63:297-303.

4. de Jong RA, Toppen NL, Ten Hoor KA, Boezen HM, Kema IP, Hollema H, Nijman HW. Status of cellular immunity lacks prognostic significance in vulvar squamous carcinoma. Gynecol Oncol. 2012; 125:186-93. https://doi. org/10.1016/j.ygyno.2011.12.416.

5. Sznurkowski JJ, Żawrocki A, Biernat W. Local immune response depends on p16INK4a status of primary tumor in vulvar squamous cell carcinoma. Oncotarget. 2017; 8:46204-10. https://doi.org/10.18632/oncotarget.17581.

6. Herbst RS, Soria JC, Kowanetz M, Fine GD, Hamid O, Gordon MS, Sosman JA, McDermott DF, Powderly JD, Gettinger SN, Kohrt HE, Horn L, Lawrence DP, et al. Predictive correlates of response to the anti-PD-L1 antibody MPDL3280A in cancer patients Nature. 2014; 515:563-7.

7. Chen DS, Mellman I. Oncology meets immunology: the cancer immunity cycle. Immunity. 2013; 39:1-10.

8. Zhao T, Li C, Wu Y, Li B, Zhang B. Prognostic value of PD-L1 expression in tumor infiltrating immune cells in cancers: a metaanalysis. PLoS One. 2017; 12: e0176822. https://doi.org/10.1371/journal.pone.0176822.

9. Kim HR, Ha SJ, Hong MH, Heo SJ, Koh YW, Choi EC, Kim EK, Pyo KH, Jung I, Seo D, Choi J, Cho BC, Yoon SO. PD-L1 expression on immune cells, but not on tumor cells, is a favorable prognostic factor for head and neck cancer patients. Sci Rep. 2016; 6:36956. https://doi.org/10. 1038/ srep36956.

10. Hou J, Yu Z, Xiang R, Li C, Wang L, Chen S, Li Q, Chen M, Wang L. Correlation between infiltration of FOXP3+ regulatory $\mathrm{T}$ cells and expression of $\mathrm{B} 7-\mathrm{H} 1$ in the tumor tissues of gastric cancer. Exp Mol Pathol. 2014; 96:284-91 https://doi.org/10.1016/j.yexmp.2014.03.005.
11. Jo JC, Kim M, Choi Y, Kim HJ, Kim JE, Chae SW, Kim $\mathrm{H}$, Cha HJ. Expression of programmed cell death 1 and programmed cell death ligand 1 in extranodal NK/T-cell lymphoma, nasal type. Ann Hematol. 2016; 96:25-31. https://doi.org/10.1007/s00277-016-2818-4.

12. Yang $\mathrm{CY}$, Lin MW, Chang YL, Wu CT, Yang PC. Programmed cell death-ligand 1 expression is associated with a favourable immune microenvironment and better overall survival in stage I pulmonary squamous cell carcinoma. Eur J Cancer. 2016; 57:91-103. https://doi. org/10.1016/j.ejca.2015.12.033.

13. Palisoul ML, Mullen MM, Feldman R, Thaker PH. Identification of molecular targets in vulvar cancers. Gynecol Oncol. 2017; 146:305-13. https://doi.org/10.1016/j. ygyno.2017.05.011.

14. Howitt BE, Sun HH, Roemer MG, Kelley A, Chapuy B, Aviki E, Pak C, Connelly C, Gjini E, Shi Y, Lee L, Viswanathan A, Horowitz N, et al. Genetic basis for PD-L1 expression in squamous cell carcinomas of the cervix and vulva. JAMA Oncol. 2016; 2:518-22. https://doi. org/10.1001/jamaoncol.2015.6326.

15. Sznurkowski JJ, Zawrocki A, Biernat W. The overexpression of p16 is not a surrogate marker for highrisk human papilloma virus genotypes and predicts clinical outcomes for vulvar cancer. BMC Cancer. 2016; 16:465. https://doi.org/10.1186/s12885-016-2503-y.

16. Bloch O, Crane CA, Kaur R, Safaee M, Rutkowski MJ, Parsa AT. Gliomaspromote immunosuppression through induction of B7-H1 expression in tumor-associated macrophages. Clin Cancer Res. 2013; 19:3165-75.

17. Kuang DM, Zhao Q, Peng C, Xu J, Zhang JP, Wu C, Zheng L. Activatedmonocytes in peritumoral stroma of hepatocellular carcinoma foster immuneprivilege and disease progression through PD-L1. J Exp Med. 2009; 206:1327-37.

18. Chen J, Feng Y, Lu L, Wang H, Dai L, Li Y, Zhang P. Interferon- $\gamma$-induced PD-L1 surface expression on human oral squamous carcinoma via PKD2 signal pathway. Immunobiology. 2012; 217:385-93.

19. Parsa AT, Waldron JS, Panner A, Crane CA, Parney IF, Barry JJ, Cachola KE, Murray JC, Tihan T, Jensen MC, Mischel PS, Stokoe D, Pieper RO. Loss of tumor suppressor PTEN function increases B7-H1 expression and immunoresistance in glioma. Nat Med. 2007; 13:84-8.

20. Marzec M, Zhang Q, Goradia A, Raghunath PN, Liu X, Paessler M, Wang HY, Wysocka M, Cheng M, Ruggeri BA, Wasik MA. Oncogenic kinase NPM/ALK induces through STAT3 expression of immunosuppressive protein CD274 (PDL1, B7-H1). Proc Natl Acad Sci U S A. 2008; 105:20852-7.

21. Straub M, Drecoll E, Pfarr N, Weichert W, Langer R, Hapfelmeier A, Götz C, Wolff KD, Kolk A, Specht K. CD274/PD L1 gene amplification and PDL1 protein expression are common events in squamous cell carcinoma of the oral cavity. Oncotarget. 2016; 7:12024-34. https://doi. org/10.18632/oncotarget.7593. 
22. Ikeda S, Okamoto T, Okano S, Umemoto Y, Tagawa T, Morodomi Y, Kohno M, Shimamatsu S, Kitahara H, Suzuki Y, Fujishita T, Maehara Y. PD-L1 is upregulated by simultaneous amplification of the PD-L1 and JAK2 genes in non-small cell lung cancer. J Thorac Oncol. 2016; 11:62-71.

23. Mittendorf EA, Philips AV, Meric-Bernstam F, Qiao N, Wu Y, Harrington S, Su X, Wang Y, Gonzalez-Angulo AM, Akcakanat A, Chawla A, Curran M, Hwu P, et al. PD-L1 expression in triple-negative breast cancer. Cancer Immunol Res. 2014; 2:361-70.

24. Mu CY, Huang JA, Chen Y, Chen C, Zhang XG. High expression of PD-L1 in lung cancer may contribute to poor prognosis and tumor cells immune escape through suppressing tumor infiltrating dendritic cells maturation. Med Oncol. 2011; 28:682-8.

25. Song M, Chen D, Lu B, Wang C, Zhang J, Huang L, Wang X, Timmons CL, Hu J, Liu B, Wu X, Wang L, Wang J, Liu H. PTEN loss increases PD-L1 protein expression and affects the correlation between PD-L1 expression and clinical parameters in colorectal cancer. PLoS One. 2013; 8:e65821.

26. Konishi J, Yamazaki K, Azuma M, Kinoshita I, DosakaAkita H, Nishimura M. B7-H1 expression on non-small cell lung cancer cells and its relationship with tumor-infiltrating lymphocytes and their PD-1 expression. Clin Cancer Res. 2004; 10:5094-100.

27. Taube JM, Anders RA, Young GD, Xu H, Sharma R, McMiller TL, Chen S, Klein AP, Pardoll DM, Topalian SL, Chen L. Colocalization of inflammatory response with B7-h1 expression in human melanocytic lesions supports an adaptive resistance mechanism of immune escape. Sci Transl Med. 2012; 4:127ra137.

28. Lipson EJ, Vincent JG, Loyo M, Kagohara LT, Luber BS, Wang H, Xu H, Nayar SK, Wang TS, Sidransky D, Anders RA, Topalian SL, Taube JM. PD-L1 expression in the Merkel cell carcinoma microenvironment: association with inflammation, Merkel cell polyoma virus and overall survival. Cancer Immunol Res. 2013; 1:54-63.

29. Droeser RA, Hirt C, Viehl CT, Frey DM, Nebiker C, Huber X, Zlobec I, Eppenberger-Castori S, Tzankov A, Rosso R, Zuber M, Muraro MG, Amicarella F, et al. Clinical impact of programmed cell death ligand 1 expression in colorectal cancer. Eur J Cancer. 2013; 49:2233-42.

30. Pardoll DM. The blockade of immune checkpoints in cancer immunotherapy. Nat Rev Cancer. 2012; 12:252-64. https:// doi.org/10.1038/nrc3239. 